\title{
THE ROLE OF THE INTERNATIONAL COMPREHENSIVE OCEAN-ATMOSPHERE DATA SET IN THE SUSTAINED OCEAN OBSERVING SYSTEM
}

\author{
Steven J. Worley ${ }^{(1)}$, Scott D. Woodruff( ${ }^{(2)}$, Sandra J. Lubker ${ }^{(2)}$, Zaihua $\mathbf{J i}^{(1)}$, J. Eric Freeman ${ }^{(3)}$, \\ Elizabeth C. Kent ${ }^{(4)}$, Philip Brohan ${ }^{(5)}$, David I. Berry ${ }^{(4)}$, \\ Shawn R. Smith ${ }^{(6)}$, Clive Wilkinson ${ }^{(7)}$, and Richard W. Reynolds ${ }^{(8)}$ \\ (1) NCAR (National Center for Atmospheric Research), 1850 Table Mesa Drive, Boulder, CO 80305, USA, \\ Email: worley@ucar.edu; zji@ucar.edu \\ ${ }^{(2)}$ NOAA/ESRL (National Oceanic and Atmospheric Administration/Earth System Research Laboratory) (R/PSD3), \\ 325 Broadway, Boulder, CO 80305, USA, Email: Scott.D.Woodruff@noaa.gov; Sandra.J.Lubker@noaa.gov \\ ${ }^{(3)}$ NOAA/NCDC/CDMP (National Oceanic and Atmospheric Administration/National Climate Data Center/Climate \\ Database Modernization Program), 151 Patton Avenue, Asheville, NC 28801, USA, Email: Eric.Freeman@noaa.gov \\ ${ }^{(4)}$ National Oceanography Centre, Waterfront Campus, European Way, Southampton, SO14 3ZH, United Kingdom, \\ Email:eck@noc.ac.uk; dyb@noc.ac.uk \\ ${ }^{(5)}$ Met Office, FitzRoy Road, Exeter, EX1 3PB, United Kingdom, Email: philip.brohan@metoffice.gov.uk \\ ${ }^{(6)}$ COAPS (Center for Ocean-Atmospheric Prediction Studies), Florida State University, 236 R. M. Johnson Bldg. \\ 32306-2840 Tallahassee USA, Email: smith@coaps.fsu.edu \\ (7) University of East Anglia, CRU (Climatic Research Unit), University Drive, Norwich, NR4 7TJ United Kingdom, \\ Email: c.w.wilkinson@uea.ac.uk \\ ${ }^{(8)}$ NOAA/NCDC (National Oceanic and Atmospheric Administration/National Climate Data Center), 151 Patton \\ Avenue, Asheville, NC 28801, USA, Email: Richard.W.Reynolds@noaa.gov
}

\begin{abstract}
The International Comprehensive Ocean-Atmosphere Data Set (ICOADS) is an archive of in situ marine surface observations and products, which has been developed over 25 years. The current Release 2.5 spans 1662-2007 and has preliminary monthly updates for 2008 onwards. ICOADS is a worldwide respected reference dataset, combining data from multiple sustained ocean observing systems. In this paper, the impact of ICOADS on associated advanced data products and research is reviewed, the improvements in data composition and coverage relative to the previous Release are illustrated, the positive influence and support from the international collaborators is described, the free and open access is recounted, and the future objectives and recommendations to the community are defined.
\end{abstract}

\section{INTRODUCTION}

ICOADS contains marine surface data spanning the past three centuries. The archive was first made available over 25 years ago and each new Release has brought improvements that have benefited research, education, and commercial marine operations. The objectives of ICOADS remain: to collect as much original estimated (non-instrumental) and measured surface in situ data as possible; to treat each observation systematicallypreserving data source identification and measurement metadata with each record, and converting units and coding schemes to a uniform set; to perform basic quality checks; and to freely distribute the data and products worldwide. The observations within ICOADS are from many different observing systems encompassing the evolution of measurement technology over hundreds of years, resulting in the world's most extensive marine meteorological data archive.

The observations from ICOADS have been used in a wide range of applications including, amongst others: quantifying marine climate change on the centennial time-scale, assimilation into reanalysis models, satellite validation and calibration, and air-sea interaction studies. Additionally, international research teams have taken special interest in specific variables, improving upon the accuracy of the observations and developing derived products. In many cases, the improvements have been published and the data made available, we highlight just a few. Global visually estimated wave data have been processed and summarized [12]. Global gridded sea surface temperature (SST) datasets have been generated using data from ICOADS amongst other sources on a range of space and time scales [39 and [27]. These vary from monthly datasets spanning a century or longer (e.g. [17], [25], [26] and [32]) to weekly and daily datasets spanning the last few decades (e.g. [28] and [29]). Gridded datasets containing estimates of humidity [36 and [2], sea level pressure [18] and 1], air temperature [25] and [2] and wind speed [2] have similarly been developed using observations from ICOADS. ICOADS-derived datasets have been used in assessments of climate change, such as those by the Intergovernmental Panel on Climate Change (IPCC e.g. [3]). Further information on the uses of ICOADS, including applications in calibration and validation of satellite data and model output, is given by [22].

Fluxes at the ocean-atmosphere interface are critical for understanding the earth system [9]. Direct in situ 
measurements are possible, however these require expensive instrumentation and detailed information about the motion of the ships or other platforms, the location of the instruments and the flow distortion over the platform. As a result, these measurements are typically only made on Research Vessels (RVs), resulting in direct flux measurements that are limited in both time and space. In order to make in situ estimates over decadal time-scales, and with a wide spatial coverage, bulk parameterizations [10] are used with Voluntary Observing Ship (VOS) reports that include the full complement of sea surface conditions, i.e. SST, air temperature, wind, humidity, cloud, and weather information [22]. The VOS observations from ICOADS and its predecessors have a long history of being used in such datasets (e.g. [7], [30], [16], [31], [4] and[2]).

When using ICOADS today for climate research and air-sea interaction studies there are growing requirements for high degrees of accuracy, and for detailed assessments of data characteristics, including biases and errors. Heterogeneities in instrumental and observational practices, as well as in spatial and temporal sampling, are replete in ICOADS, and thus form a significant challenge to achieving this goal. However, in ICOADS we continue to seek to provide as much information as possible that will permit estimation of the impact of errors, such observational and data source metadata has been used to make data adjustments (e.g. [2]). Many ICOADS-derived datasets now contain uncertainty estimates (e.g. [25], [17] and [2]) and the effects of sampling heterogeneity on gridded datasets have been quantified [13] and [14].

During the past decade, global atmospheric reanalyses have been an important tool for climate change research. The models used in these reanalysis projects assimilate vast quantities of in situ and remotely sensed data. Invariably ICOADS has been a significant part of the reference dataset for the ocean surface. The National Oceanic and Atmospheric Administration (NOAA), European Centre for Medium Range Weather Forecasts (ECMWF), Japan Meteorological Agency (JMA), and the National Aeronautics and Space Administration (NASA) have all taken advantage of ICOADS for their reanalyses. Communication between centers performing reanalyses and the ICOADS developers is excellent. Use of ICOADS reduces the effort required for data preparation and quality control (QC) for reanalysis projects as use of the latest available ICOADS Release automatically includes all new data sources, and any other added value from marine data experts. In a complementary manner, reanalyses efforts also uncover data problems in ICOADS that feedback to its developers and lead to future improvements.

The remainder of the paper will identify the community that develops and contributes to ICOADS, and describe the key publications and general characteristics of and access to the observational data and products. Release 2.5 (R2.5) - our latest available update to ICOADS; spanning 1662-2007, and coupled with monthly updates for 2008 onwards - is also reviewed, together with project objectives and recommendations.

\section{ICOADS COMPOSITION}

ICOADS represents the largest collection of surface in situ marine data currently available. Data sources include commercial and military ships, RVs, moored and drifting buoys, platforms and some coastal and island data. Some data, such as those from RVs [33] or the moored [24] and drifting buoys [19] are available in other archives, but the strength of ICOADS is that it brings all data sources together in a common format, and contains much data not available from any other source. The observations include SST, air temperature, humidity, surface pressure, wind speed and direction, wind wave and swell heights, directions and periods, cloud cover, types and heights, weather codes, ice information; plus reported (and some delayed-mode) metadata elements.

ICOADS makes data available in the new International Maritime Meteorological Archive (IMMA) data format [38]. The IMMA format is under consideration as an international standard for JCOMM, and has now fully replaced the more limited binary format previously used for ICOADS. IMMA is an ASCII-based format with a fixed "core" set of the most commonly reported variables, to which an arbitrary number of data "attachments" can be made (for metadata, QC flags, etc.). In one of these attachments, original input data are now always preserved as part of ICOADS translation processing, to guard against the possibility that original fields were incorrectly or incompletely translated into regular IMMA fields. This data structure is an important archiving asset of the IMMA data format.

From the beginning of the record up through the middle 1970s, ship data (VOS plus some RVs) dominate ICOADS (Fig. 1). Since then, the contributions from buoys and other automated platforms have rapidly increased, while ship data density began decreasing in 1990. On a purely record count basis, this appears to be satisfactory, but sampling characteristics of these different systems reveal some concerns. VOS equipped with observers and instruments typically report measurements of many different variables and they largely sample along the world's major shipping routes. The ship observing system also demonstrates spatial and temporal variations that can affect estimates in certain regions. As an illustration monthly snapshots, separated by 20 years, for the eastern Pacific show similar numbers of VOS ship observations but a notable decrease in US to Asia shipping lane observations and an increase in tropical observations (Fig. 2). 
$\mathrm{RVs}$, in contrast, explore a wide range of ocean areas, but typically do not visit the same locations with the regularity of the VOS fleet. In the eastern Pacific, again by simply inspecting the station location plots separated by two decades (Fig. 2), a more uniform basin-wide sampling in 1977 as compared to 1997 is evident. In 1977, Russia had a very large RV observing fleet and those reports are augmented with near-surface measurements from the World Ocean Database (WOD) [5], whereas in 1997 the RV measurements are largely from the WOD alone.

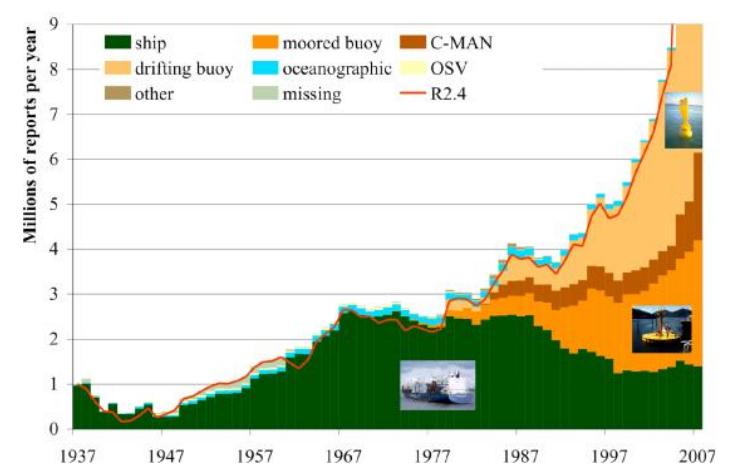

Figure 1. Annual distribution (1937-2007) of major platform types in Release 2.5. The vertical scale is truncated at 9M; years 2005-07 have 13M, 15M, and $16 M$ total reports, respectively. The red line shows the Release 2.4 annual counts. Ships (mainly VOS plus some $R V s$ ), buoys and oceanographic are self explanatory, Ocean (permanent) Station Vessel $=O S V$, Coastal-Marine Automated Network $=C-M A N$, ocean drilling rigs/platforms etc. $=$ other , and unidentified platform types $=$ missing. (Adapted from [39]; ship photo courtesy of www.ShipPhotos.co.uk.)

Moored buoys sample only a small portion of the global ocean, but do so with high frequency, an increasing complement of instruments in modern times, and potentially with very good accuracy because instruments can be post calibrated and high quality delayed-mode archives generated. In the eastern Pacific, example (Fig. 2), we clearly see the impact of the tropical moored buoys. They are non-existent in 1977 but, by 1997, they contribute over $50 \mathrm{~K}$ reports per month, the largest of any observing system (in that geographic area). Similarly, the NOAA National Data Buoy Center (NDBC) Coastal-Marine Automated Network (C-MAN) provides (since the 1980s) another high temporal-density, but limited spatial, addition to the observing systems represented in ICOADS.

Drifting buoys have a more ubiquitous coverage on the world's oceans, but sample only a few parameters, and since they are generally not recovered, recalibration at end-of-service life for measurement accuracy is presently problematic, although gross changes caused by instrument faults may be detectable by time series analysis. In the eastern Pacific example (Fig. 2), drifting buoys had little or no impact in the 1970s, but by 1997 they make a significant addition, and their influence is even greater today (Fig. 1).

The complex mixture of data observing systems over time and space presents challenges when the highest accuracy and error estimation are required. However, ICOADS, through metadata fields in the records, offers support and continues to improve the information whenever possible to aid in the data evaluation process.

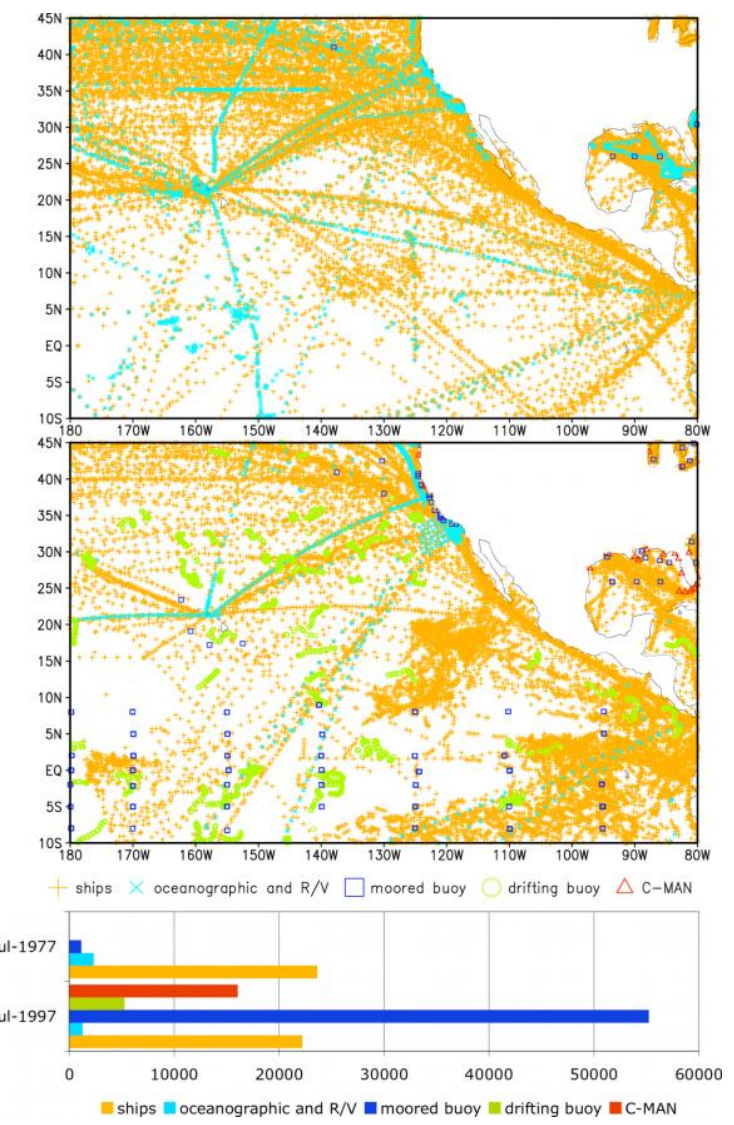

Figure 2. Snapshot spatial distribution of major platform types in the eastern Pacific Ocean from Release 2.5. Top panel is July 1977 and middle panel is July 1997.

The bottom panel summarizes the total numbers of reports marked on the 1977 and 1997 panels, separately by major platform type. The buoy and C-MAN platform categories are as for Fig. 1; the remaining categories differ from Fig. 1 in that the RV data have been combined with oceanographic data (here "ships" refers to VOS only).

\section{RELEASE 2.5}

ICOADS R2.5 forms the latest version of ICOADS and is a major update, merging the 238 million $(\mathrm{M})$ records from the previous Release 2.4 (R2.4) with many newly available or improved data. The new data have been 
subjected to duplicate analysis and elimination, quality checked against climatologies and with other QC flags and indicators set, pre-conditioned to fix specific problems and remove suspect data, and the resultant output compared to R2.4. R2.5 has $261 \mathrm{M}$ records covering 1662 though 2007 and is a blend of delayedmode and Global Telecommunication System (GTS) real-time data, with delayed-mode records preferentially selected where duplicates are detected.

Coincident with $\mathrm{R} 2.5$, is a new procedure to extend ICOADS to near-real-time with the best available GTS records. This observational supplement to ICOADS (currently based exclusively on the NOAA National Centers for Environmental Prediction (NCEP) GTS data) is updated monthly and lags real-time by two to six weeks. These data are subjected only to basic quality checks but conform to the IMMA data format [38]. This product is replacing an existing near-real-time ASCIIformatted product containing only a limited selection of data fields. The rest of this section focuses on the new aspects of R2.5. Details about the overall data source composition, data format, and successful strategies for handling the wide variety of marine surface data are given in [41].

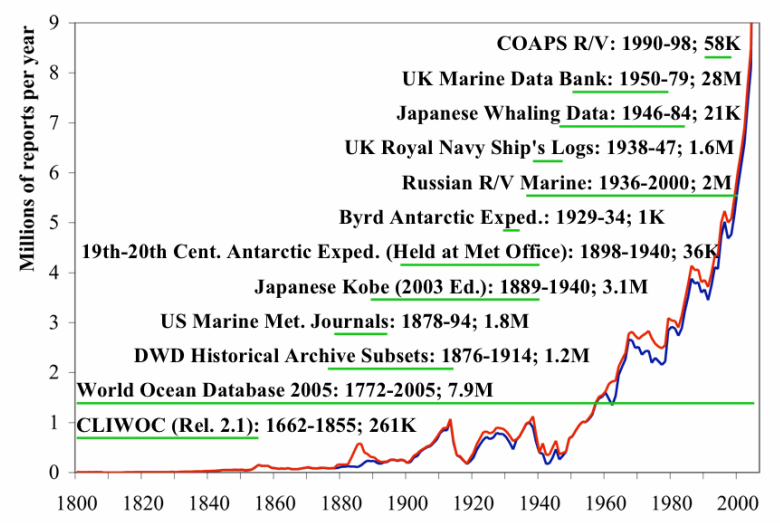

Figure 3. Major historical data sources added to Release 2.5. Horizontal green lines illustrate the time range of the original data sources. The annual numbers of reports for Release 2.4 is shown by the blue line and

Release 2.5 by the red line. As in Fig. 1 the vertical scale is truncated at 9M. Data coverage prior to 1800 is very sparse.

One of the key improvements to R2.5 include the addition of a number of new or replacement data sources, ranging from newly digitized data unique to ICOADS, such as the US Marine Meteorological Journals spanning 1878-94, to replacement of sources previously used with updated versions, e.g. the replacement of earlier versions of the WOD with data from the latest version, World Ocean Database 2005.
These new data sources improve ICOADS by extending the record covered both forward and backward in time and Fig. 3 illustrates the major new additions and replacement data sources in $\mathrm{R} 2.5$.

In addition to the new data sources, a substantial amount of GTS data has been replaced with higher quality delayed-mode data. In R2.4 the majority of ship observations from 1998 onwards were GTS reports. In contrast, for R2.5 a large number of these observations have been replaced, with approximately $50 \%$ of the ship observations in this period from delayed-mode data collections (Fig. 4), primarily the higher quality and more complete logbook data. The drifting buoy data in the period 2005-07 have been improved in R2.5 by the replacement of the lower quality GTS records used in the previous Release with delayed-mode data. Only minor changes have been made in the moored buoy record in $\mathrm{R} 2.5$ compared to $\mathrm{R} 2.4$, with a major change being the inclusion of air humidity observations. Further details on the replacement of the GTS data with delayed-mode data and the improvements made are given in [41].
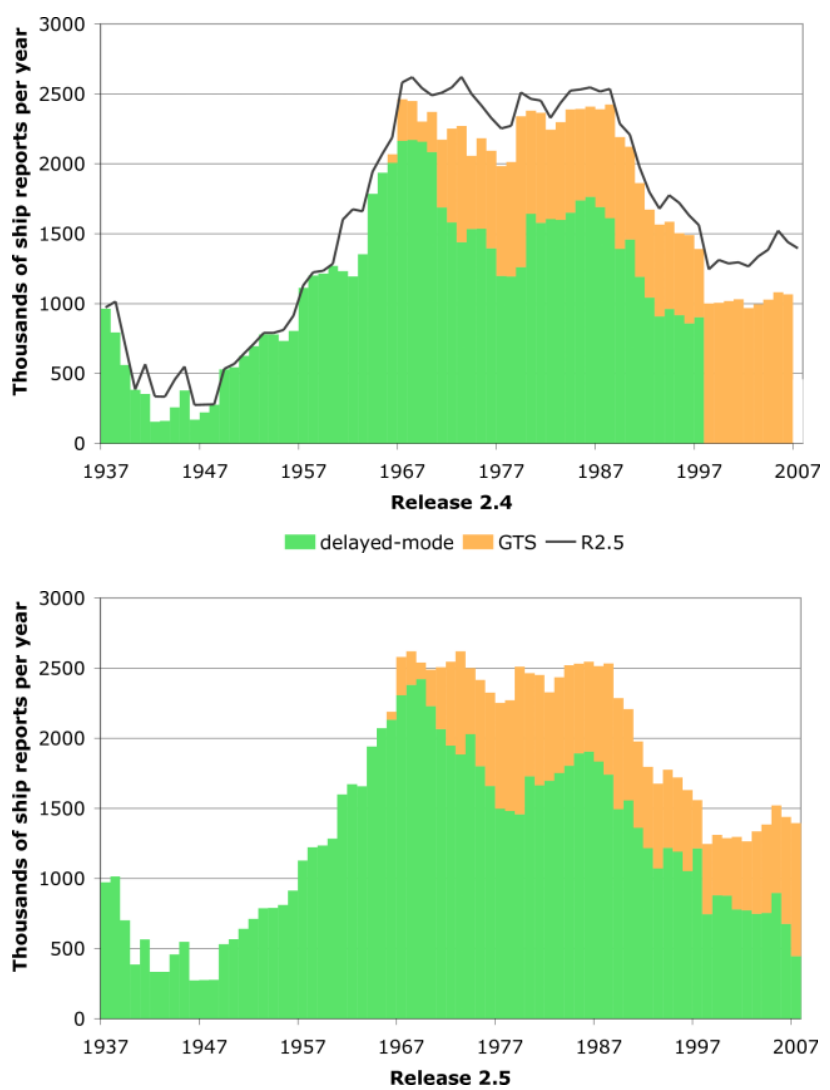

Figure 4. Annual distribution (1937-2007) of delayedmode and GTS ship data (mainly VOS and some RVs) in Release 2.4 (top; note: 2007 not shown because Release 2.4 ended in May) and Release 2.5 (bottom). The black line in the top panel contrasts the resultant Release 2.5 distribution. 
Following long-established practices, simple monthly summary statistics of ICOADS observations have been created from quality controlled R 2.5 observations for $2^{\circ}$ latitude by longitude squares beginning in 1800 and $1^{\circ}$ squares beginning in 1960. Eight observed variables (comprising sea surface and air temperatures, wind speed and components, sea level pressure, total cloudiness, and relative and specific humidity), and 14 derived variables, are summarized using a set of 10 statistics, e.g. mean, median, number of observations [42]. These summary statistics are considered to be a baseline product, because no attempt is made to account for observing system changes and measurement biases, but the many variables are treated consistently and the observation types grouped in different ways and with different levels of outlier trimming applied to provide a good product for first order environmental assessment.

\section{THE NATIONAL AND INTERNATIONAL CONTRIBUTING COMMUNITY}

ICOADS has grown from a US-centric effort by three partners (the NOAA Earth System Research Laboratory (ESRL) and National Climatic Data Center (NCDC), and the National Center for Atmospheric Research (NCAR)), to an expanded US and international partnership. This has been achieved by developing international links, including with the Joint World Meteorological Organisation (WMO)/Intergovernmental Oceanographic Commission (IOC) Technical Commission for Oceanography and Marine Meteorology (JCOMM). This growth has added value to ICOADS in many ways: new data sources have been uncovered and contributed; expert knowledge has enabled data improvements spanning the early sailing fleets; ship and measurement metadata have been digitized and included alongside observations; and data uncertainty has been quantified, just to name a few.

Data provision, collation, and distribution remain the responsibility of the three founding partners, but other noteworthy contributions are GTS data from NCEP, marine surface meteorological observations and nearsurface profile temperatures collected by the NOAA National Oceanographic Data Center (NODC) into the WOD, and environmental US moored buoy and CMAN data from NDBC. Data from tropical moored buoy arrays-so far mainly the Tropical Atmosphere Ocean/TRIangle Trans-Ocean buoy Network (TAO/TRITON) array in the Pacific, and the Prediction and Research Moored Array in the Atlantic (PIRATA) - are provided by the NOAA Pacific Marine Environmental Laboratory (PMEL), NDBC, and by the Japan Agency for Marine-Earth Science and Technology (JAMSTEC). The Center for OceanAtmospheric Prediction Studies (COAPS) at Florida State University contributes high-resolution observations from the ocean research vessel fleet.
Integrated Science Data Management (ISDM) of Fisheries and Oceans - Canada, provides the drifting buoy data archive, plus some quality controlled moored buoy data.

The early observations in ICOADS have been augmented with $17^{\text {th }}-20^{\text {th }}$ century data and metadata from a number of multi-national projects. These include the RECovery of Logbooks And International Marine data (RECLAIM; http://icoads.noaa.gov/reclaim/) [35], Climatological database for the World's Oceans (CLIWOC) [11], Atmospheric Circulation Reconstruction over the Earth (ACRE; http://www.metacre.org/), and Global Oceanographic Data Archaeology and Rescue (GODAR) [23] projects. In a recent joint project the UK Met Office and NOAA Climate Database Modernization Program (CDMP) have digitized, quality checked, and provided data held in UK archives [6] and historical publications.

On a quarterly basis the JCOMM Global Collecting Centres (GCCs) distribute worldwide delayed-mode (i.e., paper or electronic logbook) VOS data, currently from about 26 contributing members. The UK National Oceanography Centre, Southampton contributes quality checked ship metadata from WMO [20]. Beyond the most active recent and ongoing major programs noted above there are many others including substantial contributions from Europe and Asia in the past ICOADS development history ([42] see "deck" and source identifications in Tables II-III, as updated in [41]; also [37]).

Continuity and coordination for ICOADS has been promoted by two series of meetings that began over a decade ago. The JCOMM Workshops on Advances in Marine Climatology (CLIMAR) were held in Vancouver, Canada, 1999, Brussels, Belgium, 2003, and Gydnia, Poland, 2008 [8]. Alternating approximately biennially with CLIMAR, the Workshops on Advances in the Use of Historical Marine Climate Data (MARCDAT) have been held in Boulder, Colorado, USA, 2002, and Exeter, UK, 2005 [21]. Sponsors of past meetings have included WMO, the Global Climate Observing System (GCOS) and the Climate Variability and Predictability Project (CLIVAR). These meetings have done much to guide the development of ICOADS.

\section{ACCESS}

Currently the ICOADS data are maintained with free and open access worldwide, and no restrictions on redistribution, from the US partners. There are a variety of access schemes and data formats available through the project website (http://icoads.noaa.gov/). The complete observations are available in the IMMA format [38], and the complete monthly summary statistics are available in binary and netCDF (Network Common Data Form) formats. Parameter, temporal, and 
spatial subsetting are available for the observations and statistics, yielding simplified ASCII (American Standard Code for Information Interchange) formatted text files. Subsetting and plotting also augment the netCDF file service. When combined, these services address the requests of over 400 unique users per year from the three US partners. This metric is a minimum estimate; since there is no limit on data sharing or redistribution it is certain that ICOADS reaches many more users, including through reanalysis and other value-added products that ingest it.

More can also be done to aid users in accessing the data and creating network interoperability [15]. Rapidly served queries can easily be supported by the combination of a web interface and connected databases holding all the ICOADS observational data. NCDC plans to initiate such a system in the future. Also interoperability can be supported by the OPeNDAP (Open-source Project for a Network Data Access Protocol) and THREDDS (Thematic Real-time Environmental Distributed Data Services) server; technologies made available by Unidata (http://www.unidata.ucar.edu/). Another option includes the GrADS (Grid Analysis and Display System) Data Server (GDS (GrADS-DODS Server), http://www.iges.org/grads/gds/). These options are currently not offered directly from the ICOADS partners because funding support is not available and some computer security concerns need to be addressed. To better facilitate international availability of ICOADS data and products, links between these technologies and the new WMO Information System (WIS) and WMO Integrated Global Observing Systems (WIGOS; http://www.wmo.int/pages/prog/www/wigos/) are planned.

\section{FUTURE OBJECTIVES}

Future enhancements to ICOADS include: the addition of more new data sources; leveraging linkages with JCOMM and WMO programs; efforts to expand metadata; database driven and interoperable access; and potentially the development of a user accessible, corrected and bias adjusted ICOADS archive for climate studies.

Many new historical ship datasets exist in various stages of preparation and could be added to ICOADS. The datasets that are most ready for addition are in digital form and require format conversion and quality checks to prepare them for the data processing steps that merge new sources into the archive. Other datasets exist only as images and are yet to be fully digitized. Even further removed from being available, there are many collections in printed (or published) form that if imaged and then digitized would improve the early period global coverage. Principal members of the ICOADS project and several active programs (e.g. RECLAIM, ACRE, CDMP) help discover and track these sources, and when possible arrange for digitization and ultimately contribution to ICOADS. In addition to [35], information on the status of other potential new data sources can be obtained on the RECLAIM home page (http://icoads.noaa.gov/reclaim/).

We also seek to improve the representation of modern ship and buoy data in ICOADS. The meteorological and oceanographic RVs are under-represented in the archive. Recent work at COAPS and through the Shipboard Automated Meteorological and Oceanographic System (SAMOS) initiative is improving upon this situation and has added data from the World Ocean Circulation Experiment (1990-98) into R2.5. Expansion and support for this effort would be an important asset for ICOADS and procedures are being developed to make this a routine part of SAMOS data archiving practices [33]. The inclusion of meteorological observations from the WOD has also been helpful in this regard. Furthermore, all delayedmode VOS and VOS Climate (VOSClim) data from contributing maritime nations [22] are critical components for ICOADS. A planned modernization of the delayed-mode VOS system under JCOMM could lead to multiple benefits: increasing the quantity of full meteorological reports from ships [22], providing a secure environment for the handling of time-sensitive information such as ship identifiers, creating more accurate marine reference data and products, and potentially even better observational data as new quality control schemes are initiated [40].

Data collected over multiple centuries use many different observation methods and a variety of modern observing systems. These changes will reduce data assessment accuracy unless the observing system heterogeneities can be addressed. Metadata about ships, buoys, instrument locations, sampling methods, and observing practices and codes are needed to begin making bias adjustments, corrections, and error estimates. ICOADS has traditionally captured and carried the basic metadata that are attached to each reported record. However, the amount of metadata available this way is very dependent on the observing system used. We have improved upon this basic set by including selected VOS metadata available from WMO [20], but much more work is needed. Improvement and expansion of the ship metadata would be helpful and, critically, methods and formats need to be devised (operationally under JCOMM) so a time history of buoy metadata can be archived and uniquely linked to the individual records.

Reanalysis (and operational Numerical Weather Prediction) data assimilation models are another potential source of metadata. For example, differences between the modelled and observed values can serve as 
a quality check on the observed data. Random and systematic outliers often stand out against the model field. Metadata of this type can serve multiple purposes: to evaluate and possibly correct the archive, e.g. since systematic errors can sometimes easily be accounted for by incorrectly positioned records; provided to users as additional QC feedback information that can be factored into their studies; and likewise so that subsequent reanalyses can take advantage of previous reanalyses.

Adding data from the $19^{\text {th }}$ century and before to ICOADS is also presenting new challenges in metadata handling. There is often considerable uncertainty about how these early data should be processed and converted to the standard IMMA format. As a result, it is critical to preserve the original data as part of the IMMA records, and documentation (and as feasible software) reflecting how the conversions were done. These and other factors will likely in the future require refinements and extensions to the IMMA data format.

The international community has had organized discussions about a program that would create an enhanced version of ICOADS including bias adjustments that could selectively be applied to the observations. Community experts have done significant work on specific variables and time periods to improve the homogeneity across observing systems, estimating the uncertainty of observations, improve duplicate elimination and identifying incorrectly positioned data through ship tracking. These activities typically result in analyzed gridded datasets [2], [4], [12], [16], [17, [18], [25], [26], [28], [30], [31] and [36]. The idea is to make the underlying observations used in these improved datasets available to all ICOADS users, i.e. create an "advanced" or "Climate-ICOADS" archive. There are many details to be fleshed out and suitable funding across the international groups needs to be identified.

Some elements of the proposed collaborative program are: a single central group will be responsible to maintain Climate-ICOADS in a database where each record can be uniquely identified; all the original data fields will remain unaltered; the international teams will develop adjustments for variables in their area of expertise; the adjustments are to be documented and vetted among the program participants; the adjustments will be submitted to the central group where they can be precisely associated to the original records in a database; the access interface will inform users about what adjustments are available and the documentation about the adjustments will also be readily available; and the users will be able to select data in subsets by time, space, variable, and correction. The proposed system would be dynamic and continuously evolve as recommended adjustments are evaluated, reviewed, and refined. These observations could support a new broad set of statistical or analyzed summary products.

\section{RECOMMENDATIONS}

- Support for ICOADS at the current set of contributing institutions and laboratories should be proudly recognized and additional support should be added. This is an open community and new participants are welcomed.

- Nations and organizations taking and holding marine surface observations, both historical and contemporary, should consider the value of adding their data to ICOADS [40].

- Research projects and RV operators should take account of the marine surface data they collect and ensure there is a data pathway for it to be included in ICOADS. These high-quality and possibly highresolution data can have the effect of increasing the accuracy of large-scale analyses.

- The importance of ocean observing system metadata cannot be overemphasized [34]. While the ship metadata published by WMO since 1955 only become available in delayed-mode and do not cover as many vessels as would be optimal, it is a substantial resource. Metadata for all types of buoys and automated stations are currently not easily included or linked with large global collections like ICOADS. Legacy and modern metadata need to be collected, systematically organized (formatted), and eventually made available with the ICOADS reported observations. JCOMM and the international community should continue to take action to improve collection and digital distribution of observing system metadata for all platform types.

- The CLIMAR and MARCDAT meeting series are invaluable in sustaining the international community around ICOADS and guiding its future. These meeting series should continue.

- Increased investment should be made in the ICOADS US core team. There are numerous readily available benefits: contributions from international researchers could be capitalized to support all users (e.g. Climate-ICOADS), data preparation for insertion into ICOADS could be accelerated, additional data-access tools could be deployed to further expand easy data use in the growing community doing earth system research, and more frequent Release updates would bring improvements to the users more rapidly.

\section{REFERENCES}

1. Allan, R.J. \& Ansell, T.J. (2006). A New Globallycomplete Monthly Historical Gridded Mean Sea Level Pressure Data Set (HadSLP2): 1850-2004. J. Climate 19, 5816-5842. 
2. Berry, D.I. \& Kent, E.C. (2009). A New Air-Sea Interaction Gridded Dataset from ICOADS with Uncertainty Estimates. Bull. Amer. Meteor. Soc. 90, 645-656.

3. Bindoff, N.L. \& Co-Authors (2007). Observations: Ocean Climate Change and Sea Level. Climate Change 2007: The Physical Science Basis. Contribution of Working Group I to the Fourth Assessment Report of the Intergovernmental Panel on Climate Change. Solomon, S. \& Co-Authors, Eds. Cambridge University Press, Cambridge, UK, and New York, NY, USA, 996 pp.

4. Bourassa, M.A., Romero, R., Smith, S.R. \& O'Brien, J.J. (2005). A new FSU wind climatology. J. Climate 18 3692-3704.

5. Boyer, T.P. \& Co-Authors (2006). World Ocean Database 2005, Chapter 1: Introduction. NOAA Atlas NESDIS 60. Levitus, S. Ed. U.S. Government Printing Office, Washington, DC, 190 pp., DVD.

6. Brohan, P. \& Co-Authors (2008). Marine observations of old weather. Bull. Amer. Meteor. Soc. 90, 219-230.

7. Bunker, A.F. (1976). Computations of Surface Energy Flux and Annual Air-Sea Interaction Cycles of the North Atlantic Ocean. Mon. Wea. Rev. 104, 1122-1140.

8. Charpentier, E. \& Co-Authors (2008). Third JCOMM Workshop on Advances in Marine Climatology (CLIMAR-III). MeteoWorld, December 2008.

9. Fairall, C. \& Co-Authors (2010). "Observations to Quantify Air-Sea Fluxes and their Role in Climate Variability and Predictability" in these proceedings (Vol. 2), doi:10.5270/OceanObs09.cwp.27.

10. Fairall, C.W., Bradley, E.F., Hare, J.E., Grachev, A.A. \& Edson, J.B. (2003). Bulk parameterization of air-sea fluxes: Updates and verification for the COARE algorithm. J. Climate 16, 571-591.

11. García-Herrera, R. \& Co-Authors (2005). CLIWOC: A Climatological Database for the World's Oceans 17501854. Climatic Change 73, 1-12.

12. Gulev, S.K. \& Grigorieva, V. (2006). Variability of the winter wind waves and swell in the North Atlantic and North Pacific as revealed by the Voluntary Observing Ship Data. J. Climate 19, 5667-5785.

13. Gulev, S.K., Jung, T. \& Ruprecht, E. (2007). Estimation of the impact of sampling errors in the VOS observations on air-sea fluxes. Part I. Uncertainties in climate means. J. Climate, 20, 279-301.

14. Gulev, S.K., Jung, T. \& Ruprecht, E. (2007). Estimation of the impact of sampling errors in the VOS observations on air-sea fluxes. Part II. Impact on trends and interannual variability. J. Climate 20, 302-315.

15. Hankin, S. \& Co-Authors (2010). "NetCDF-CFOPeNDAP: Standards for Ocean Data Interoperability and Object Lessons for Community Data Standards Processes" in these proceedings (Vol. 2), doi:10.5270/OceanObs09.cwp.41.
16. Josey S.A., Kent, E.C. \& Taylor, P.K. (1999). New Insights into the Ocean Heat Budget Closure Problem from Analysis of the SOC Air-sea Flux Climatology. $J$. Climate 12, 2856-2880. doi:10.1175/15200442(1999)012<2856:NIITOH>2.0.CO;2.

17. Kaplan, A., Cane, M.A., Kushnir, Y., Clement, A.C., Blumenthal, M.B. \& Rajagopalan, B. (1998). Analyses of global sea surface temperature 1856-1991. $J$. Geophys. Res. 103(C9), 18567-18589.

18. Kaplan, A., Kushnir, Y. \& Cane, M. A. (2000). Reduced space optimal interpolation of historical marine sea level pressure: 1854-1992. J. Climate 13, 2987-3002.

19. Keeley, R., Pazos, M. and Bradshaw, B., (2010). "Data Management System for Surface Drifters" in these proceedings (Vol. 2), doi:10.5270/OceanObs09.cwp.47.

20. Kent, E.C., Woodruff, S.D. \& Berry, D.I. (2007). Metadata from WMO Publication No. 47 and an assessment of voluntary observing ship observation heights in ICOADS. J. Atmos. Oceanic Technol., 24, 214-234.

21. Kent, E. \& Co-Authors (2007). Advances in the use of historical marine climate data (Second International Workshop on Advances in the Use of Historical Marine Climate Data). Bull. Amer. Meteor. Soc. 88, 559-564.

22. Kent, E. \& Co-Authors (2010). "The Voluntary Observing Ship (VOS) Scheme" in these proceedings (Vol. 2), doi:10.5270/OceanObs09.cwp.48.

23. Levitus, S. \& Co-Authors. (2005). Building ocean profileplankton databases for climate and ecosystem research. NOAA Tech. Report 117, 29 pp. (Available from NODC/NOAA, E/OC5, 1315 East West Highway, Silver Spring MD, 20910, USA).

24. McPhaden, M. \& Co-Authors (2010). "The Global Tropical Moored Buoy Array" in these proceedings (Vol. 2), doi:10.5270/OceanObs09.cwp.61.

25. Rayner, N.A. \& Co-Authors, A. (2003). Global analyses of sea surface temperature, sea ice, and night marine air temperature since the late nineteenth century. $J$. Geophys. Res. 108(D14), 4407, doi:10.1029/2002JD002670.

26. Rayner, N.A. \& Co-Authors. (2006). Improved analyses of changes and uncertainties in sea surface temperature measured in situ since the mid-nineteenth century: the HadSST2 data set. J. Climate 19(3), 446-469.

27. Rayner, N. \& Co-Authors (2010). "Evaluating Climate Variability and Change from Modern and Historical SST Observations" in these proceedings (Vol. 2), doi:10.5270/OceanObs09.cwp.71.

28. Reynolds, R.W., Rayner, N.A., Smith, T.M., Stokes, D.C \& Wang, W. (2002). An improved in situ and satellite SST analysis for climate. J. Climate 15, 1609-1625.

29. Reynolds, R.W., Smith, T.M., Liu, C., Chelton, D.B., Casey, K.S. \& Schlax, M.G. (2007). Daily Highresolution Blended Analyses for sea surface temperature. J. Climate 20, 5473-5496 
30. da Silva, A.M., Young, A.C. \& Levitus, S. (1994). Atlas of surface marine data 1994, Vol. 1.: Algorithms and procedures. Tech. Rep. 6, US Department of Commerce, NOAA, NESDIS, 1994.

31. Smith, S.R., Servain, J., Legler, D.M., Stricherz, J.N., Bourassa, M.A. \& O'Brien, J.J. (2004). In-situ based pseudo-wind stress products for the tropical oceans. Bull. Amer. Meteor. Soc. 85, 979-994.

32. Smith, T.M., Reynolds, R.W., Peterson, T.C. \& Lawrimore, J. (2008). Improvements to NOAA's Historical Merged Land-Ocean Surface Temperature Analysis (1880-2006). J. Climate 21, 2283-2296.

33. Smith, S. \& Co-Authors (2010). "The Data Management System for the Shipboard Automated Meteorological and Oceanographic System (SAMOS) Initiative" in these proceedings (Vol. 2), doi:10.5270/OceanObs09.cwp.83.

34. Snowden, D. \& Co-Authors (2010). "Metadata Management in Global Distributed Ocean Observation Networks" in these proceedings (Vol. 2), doi:10.5270/OceanObs09.cwp.84.

35. Wilkinson, C., Woodruff, S. D., Brohan, P., Claesson, S., Freeman, E., Koek, F., Lubker, S. J., Marzin, C. and Wheeler, D. (2011), Recovery of logbooks and international marine data: the RECLAIM project. Int. $J$. Climatol., 31, 7, 968-979, doi:10.1002/joc.2102.

36. Willett, K.M., Jones, P.D., Gillett, N.P. \& Thorne, P.W. (2008). Recent Changes in Surface Humidity: Development of the HadCRUH Dataset. J. Climate 21, 5364 - 5383.

37. Woodruff, S.D., Diaz, H.F., Worley, S.J., Reynolds, R.W. \& Lubker, S.J. (2005). Early ship observational data and ICOADS. Climatic Change 73, 169-194.

38. Woodruff, S.D., 2007: Archival of data other than in IMMT format: The International Maritime Meteorological Archive (IMMA) Format. Second Session of the JCOMM Expert Team on Marine Climatology (ETMC), Geneva, Switzerland, 26-27 March 2007, JCOMM Meeting Report No. 50, 68-101.

39. Woodruff, S.D., Diaz, H.F., Kent, E.C., Reynolds, R.W. \& Worley, S.J. (2008). The evolving SST record from ICOADS. In Climate Variability and Extremes during the Past 100 Years (S. Brönnimann, J. Luterbacher, T. Ewen, H.F. Diaz, R.S. Stolarski, and U. Neu, Eds.), Advances in Global Change Research, Vol. 33, Springer, 65-83.

40. Woodruff, S. \& Co-Authors (2010). "Surface In Situ Datasets for Marine Climatological Applications" in these proceedings (Vol. 2), doi:10.5270/OceanObs09.cwp.93.

41. Woodruff, S. D., Worley, S. J., Lubker, S. J., Ji, Z., Eric Freeman, J., Berry, D. I., Brohan, P., Kent, E. C., Reynolds, R. W., Smith, S. R. and Wilkinson, C. (2011), ICOADS Release 2.5: extensions and enhancements to the surface marine meteorological archive. Int. J. Climatol., 31, 7, 951-967, doi:10.1002/joc.2103.
42. Worley, S.J., Woodruff, S.D., Reynolds, R.W., Lubker, S.J., \& Lott, N. (2005). ICOADS Release 2.1 data and products. Int. J. Climatol. (CLIMAR-II Special Issue) 25, 823-842 doi:10.1002/joc.1166. 